Oper im 20. Jahrhundert 


\section{Oper im \\ 20. Jahrhundert}

Entwicklungstendenzen und Komponisten

Herausgegeben von Udo Bermbach

Verlag J. B. Metzler

Stuttgart $\cdot$ Weimar 
Die Deutsche Bibliothek - CIP-Einheitsaufnahme

Oper im 20. Jahrhundert :

Entwicklungstendenzen und Komponisten / hrsg. von Udo Bermbach.

- Stuttgart ; Weimar : Metzler 2000

ISBN 978-3-476-01733-8

ISBN 978-3-476-03796-1 (eBook)

DOI 10.1007/978-3-476-03796-1

Dieses Werk einschließlich aller seiner Teile ist urheberrechtlich geschützt. Jede Verwertung außerhalb der engen Grenzen des Urheberrechtsgesetzes ist ohne Zustimmung des Verlages unzulässig und strafbar. Das gilt insbesondere für Vervielfältigungen, Übersetzungen, Mikroverfilmungen und die Einspeicherung und Verarbeitung in elektronischen Systemen.

(C) 2000 Springer-Verlag GmbH Deutschland Ursprünglich erschienen bei J.B. Metzlersche Verlagsbuchhandlung und Carl Ernst Poeschel Verlag GmbH in Stuttgart 2000 


\section{Vorwort}

Das 20. Jahrhundert ist ein Jahrhundert der Unübersichtlichkeit und der widersprüchlicher Entwicklungen. Das gilt nicht nur für Politik und Gesellschaft, sondern auch für die oft totgesagte Oper. Wer zurückblickt, kann nur staunen: von Richard Strauss bis Wolfgang Rihm und Adriana Hölszky spannt sich der Bogen eines Musiktheaters, dessen Essenz sich nicht auf eine kurze Formel bringen läßt. Zu vielfältig und gegenläufig sind die Tendenzen des Opernkomponierens, zu unterschiedlich und facettenreich die Inszenierungen auf den Bühnen, als daß sich eine bilanzierende Summe eindeutig ausweisen ließe. Spätromantische Wagner-Nachfolge und italienische Belcantisten stehen neben moderner Atonalität, zeitkritische Opern, die bewußt auf Politik und Gesellschaft reagieren, neben solchen, die sich Stoffen zuwenden, in denen der Zeitbezug kaum eine Rolle spielt. Zwei totalitäre Regime, das nationalsozialistische wie das kommunistische, haben ihr Operntheater ebenso zu prägen versucht, wie in pluralistischen Demokratien auch die Musikästhetik der Oper sich pluralistisch ausdifferenziert hat.

Der vorliegende Band sucht die wichtigsten Entwicklungen des Operntheaters im 20. Jahrhundert nachzuvollziehen. Der Schwerpunkt liegt dabei auf der Oper in Deutschland. Im ersten Teil wird die Zeit im ausgehenden Kaiserreich, der Weimarer Republik, des Dritten Reiches und der beiden deutschen Nachkriegsstaaten nachgezeichnet. Aber auch die französische, russisch-sowjetische, skandinavische und amerikanische Oper wird in eigenen Beiträgen beleuchtet. Der zweite Teil bringt dann eingehende Darstellungen jener Opernkomponisten, von denen angenommen werden darf, daß sie in gewisser Weise die Entwicklung der Gattung in diesem Jahrhundert repräsentieren und so ein weit gespanntes Bild von einhundert Jahren Musiktheater vermitteln.

Den meisten Aufsätzen dieses Bandes liegen Vorträge zugrunde, die während der Wintersemester 1997/98 und 1998/99 an der Hamburger Universität gehalten worden sind. Das gilt nicht für die Beiträge von Sigrid Neef, Annette Kreutziger-Herr, Siegfried Matthus und Gerhard Schneider, die eigens für dieses Buch geschrieben worden sind. Herzlich zu danken ist Rudolf Augstein, Ehrensenator der Universität Hamburg, der durch seine finanzielle Unterstützung die Vortragsreihen wie das Buch erst ermöglicht hat.

Hamburg, im Herbst 1999

Udo Bermbach 


\title{
Inhaltsverzeichnis
}

\author{
Vorwort V \\ I \\ Entwicklungen
}

Udo Bermbach

Über einige Aspekte des Zusammenhangs von Politik,

Gesellschaft und Oper im 20. Jahrhundert 3

\author{
Jens Malte Fischer \\ Im Schatten Wagners
}

Aporien und Auswege der nachwagnerschen Opernentwicklung 28

\section{Jürgen Schläder \\ Gegen Wagner}

Theatrale und kompositorische Innovation

im Musiktheater der klassischen Avantgarde 50

Ulrike Kienzle

»Wo bleibt da der berühmte >Zeitwille $?$ ?

Romantische Enklaven im Musiktheater der Moderne 75

Nils Grosch

Zum Musiktheater der Neuen Sachlichkeit 130

Michael Walter

Oper im Dritten Reich 155

Stephan Mösch

Per aspera ad futura?

Zwischen Neuanfang und Tradition: Die Oper nach dem Zweiten Weltkrieg 183

Gerhard R. Koch

Die Gegenwartslage der Oper 221

\author{
Sigrid Neef \\ Oper in der DDR
}

Offenes Kunstwerk bei geschlossener Grenze 237 
Birgit Pauls

Die Erben des Belcanto

Italienische Oper im 20. Jahrhundert 255

Sieghart Döhring

Zwischen Welttheater und Experiment

Französisches Musiktheater im 20. Jahrhundert 282

\author{
Dorothea Redepenning \\ »... volkstümlich nach Form und Inhalt ...« \\ Überlegungen zur russisch-sowjetischen Oper 303 \\ Wolfgang Sandner \\ Skandinavische Komponisten 331 \\ Annette Kreutziger-Herr \\ What it takes »to write a real american opera " \\ Ein Jahrhundert Operngeschichte in den USA 348
}

\title{
II \\ Komponisten
}

Ulrich Schreiber

Richard Strauss 387

Hanspeter Krellmann

Arnold Schönberg 403

Uwe Schweikert

Alban Berg 429

Frank Harders-Wuthenow

Franz Schreker 445

Wolf-Dieter Peter

Leoš Janáček 476

Reinhard Ermen

Benjamin Britten 494

Eckart Kröplin

Dmitri Schostakowitsch 508 
Inhaltsverzeichnis

Klaus Zehelein

Luigi Nono 531

Hans-Klaus Jungheinrich

Hans Werner Henze 557

Christoph Blitt

Bernd Alois Zimmermann 573

Klaus Angermann

Wolfgang Rihm 601

Beatrix Borchard

Adriana Hölszky 621

Siegfried Matthus
Warum komponiere ich heute Opern? 640

Gerhard Schneider

Uraufführungsdaten von Opern im 20. Jahrhundert 647

Autorenverzeichnis 657

Register 666 